\title{
Estudo comparativo de raspados orais submetidos à técnica de citologia em meio líquido $\mathrm{e}$ citopatologia convencional
}

\author{
Comparative study of oral smears applying liquid-based cytology and conventional cytopathology
}

Eliane Pedra Dias'; Adrianna Milagres²; Janaína Barbieri dos Santos33; Carla Peixoto Valladares4; Anna Carolina Bastos de Souza ; Raquel dos Santos Pinheiro ${ }^{6}$

unitermos
Citopatologia
Citologia em meio líquido
Diagnóstico oral

\section{resumo}

Introdução: Quando comparada à técnica da citopatologia convencional (CC), a citologia em meio líquido (LBC) tem sido referida como método de desempenho superior em esfregaços cervicouterinos. Objetivo: Comparar (quantitativa e qualitativamente) esfregaços orais preparados por meio da citopatologia convencional e da LBC. Material e métodos: Foram realizados raspados em borda lateral da língua de seis indivíduos com mucosa oral de aspecto clínico normal, e testados três instrumentos de coleta: escova endocervical (cytobrush), espátula plástica e escova contida no kit da citologia em meio líquido utilizado no estudo, sendo os esfregaços submetidos à citopatologia convencional e à LBC. Resultados: A escova endocervical mostrou-se mais adequada para coleta e quanto ao método, a LBC forneceu lâminas com distribuição celular mais regular e homogênea do que a citopatologia convencional. Notou-se ainda redução da quantidade de células inflamatórias e de colônias de bactérias. Discussão: Mesmo em menor quantidade, a sobreposição celular não foi totalmente eliminada na LBC como a literatura relata, pois estava presente em algumas lâminas. Embora em amostras cervicouterinas a redução de células inflamatórias, de hemácias e de muco seja considerada uma vantagem da LBC, nos raspados orais muitas vezes esses elementos compõem aspectos significativos de determinada doença. Conclusões: A citologia em meio líquido pode ser uma nova técnica a ser somada aos exames auxiliares de diagnóstico oral, mas, apesar de apresentar alguns resultados favoráveis, ainda são necessárias adaptações ao utilizá-la no diagnóstico oral. abstract

Introduction: When compared to conventional cytopathology (CC), liquid-based cytology (LBC) has been referred to as a method of superior performance in cervical smears. Objective: To quantitatively and qualitatively compare oral smears obtained through conventional cytopathology and liquid medium cytology. Material and methods: Six individuals with normal oral mucosa had the lateral border of their tongues scraped. Three collecting instruments were tested in this process: endocervical brush (cytobrush), a plastic spatula, and the LBC kit brush. Both methods, CC and LBC, were applied. Results: The endocervical brush was the most appropriate collecting instrument; as far as method is concerned, liquid medium cytology provided slides with more regular and homogeneous cellular distribution in comparison to conventional cytopathology. There was also a reduction in the number of inflammatory cells and bacteria colonies. Discussion: Cellular overlapping was not totally eliminated in the liquid medium cytology as reported in medical literature, inasmuch as it was present in some slides, though in a smaller amount. Although in cervical samples the reduction of inflammatory cells, erythrocytes and mucus is considered an advantage of $L B C$, in oral smears these elements may represent significant aspects of some oral diseases. Conclusions: Liquid-based cytology may be an additional technique to be used with complementary exams in oral diagnosis, but despite the fact it presents some favorable results some adaptations are still necessary for its use in oral diagnosis. key words

Cytopathology

Liquid-based cytology

Oral diagnosis

1. Doutora em Anatomia Patológica; coordenadora do Programa de Pós-graduação em Patologia da Faculdade de Medicina da Universidade Federal Fluminense (UFF).

2. Mestre e doutoranda em Patologia Bucodental da UFF.

3. Mestranda em Patologia Bucodental da UFF.

4. Mestre em Patologia Bucodental da UFF.

5. Bolsista do Programa Institucional de Bolsas de Iniciação Científica (PIBIC) pela UFF.

6. Bolsista do PIBIC pela UFF.

Trabalho realizado no Centro de Ciências Médicas da Faculdade de Medicina da UFF. 


\section{Introdução}

A citopatologia é uma técnica bem conhecida e utilizada há aproximadamente 50 anos, sendo empregada com sucesso na prevenção e no diagnóstico de câncer do colo do útero, assim como de outras doenças $(4,7,9,11,16)$.

Na década de 1990 foi desenvolvida uma nova metodologia para realização da citopatologia do colo uterino: a citologia em meio líquido $(\mathrm{LBC})^{(2,9,17)}$. Para viabilizar a leitura das lâminas por computadores, era necessário um preparado que apresentasse o menor número possível de artefatos e sobreposições celulares. Assim, surgiu a LBC para atender às demandas de escrutínio computadorizado ${ }^{(18)}$.

Essa técnica é realizada mediante a suspensão e centrifugação de células provenientes do material colhido em líquido fixador, e posteriormente à deposição de uma fina camada de células sobre a lâmina, denominada de citologia de monocamada ou camada fina $a^{(2-4,7,9-11,13,16,18-20)}$. Desde a década de 1990 essa técnica vem sendo estudada e, gradativamente, está substituindo a citopatologia convencional (CC) no programa de controle do câncer de colo uterino $^{(9,17)}$.

Vários autores demonstraram e confirmaram as vantagens da $L B C$ em relação à $C C$ nos exames de colo uterino (Tabela 1) ${ }^{(2,7,18-20)}$.

A Tabela 2 relaciona algumas alterações observadas na conversão da CC para LBC, segundo Hoelund(9).
Em amostras cervicouterinas e vaginais a $\mathrm{LBC}$ tem sido referida como método de desempenho superior por proporcionar melhor representação celular, com sensibilidade aumentada para a detecção de lesões, em comparação com o preparado convencional $(2,3,9,10,17)$.

Na boca a CC pode ser importante na definição diagnóstica de lesões infecciosas como leucoplasia pilosa, candidíase, herpes e paracoccidioidomicose. Além de outras como pênfigo e até mesmo neoplasias malignas $(1,5,6,12,21)$. Também pode ser realizada nos casos em que a biópsia torna-se inviável, por ser um procedimento invasivo e doloroso que requer habilidade técnica, limitando portanto sua execução.

Em 2005, Hayama et al.(7) compararam qualitativamente a técnica de $C C$ com a $L B C$, examinando 32 indivíduos que apresentavam variadas lesões bucais. A coleta foi realizada com escova endocervical (cytobrush), confeccionando-se inicialmente um esfregaço convencional, seguido da imersão da escova em frasco contendo o líquido preservante para realização da LBC. A LBC apresentou resultados estatisticamente superiores à CC na melhora da espessura celular, da distribuição de células pelo campo de estudo e da redução do percentual de fatores de interferência, devido à formação de monocamada.

Com base na literatura, a eficiência da LBC no exame de colo uterino está comprovada ${ }^{(2,7,9,17-20)}$, mas em relação ao diagnóstico oral há poucos relatos ${ }^{(7)}$. O objetivo deste

\section{Tabela 1 Vantagens e desvantagens da LBC e CC}

\begin{tabular}{|c|c|c|}
\hline & CC & LBC \\
\hline \multirow[t]{3}{*}{ Vantagens } & $\begin{array}{l}\text { Padrão-ouro por } 50 \text { anos no controle de câncer } \\
\text { cervical }\end{array}$ & Melhor preservação celular \\
\hline & Confortável em sua execução & Melhor disposição das células \\
\hline & $\begin{array}{l}0 \text { material está pronto para corar assim que é } \\
\text { recebido no laboratório }\end{array}$ & $\begin{array}{l}\text { Maior facilidade de interpretação, com redução } \\
\text { do tempo de leitura }\end{array}$ \\
\hline \multirow[t]{8}{*}{ Desvantagens } & \multirow{5}{*}{$\begin{array}{l}\text { Aproximadamente } 80 \% \text { do material permanecem } \\
\text { aderidos à escova, sendo descartados após a } \\
\text { coleta }\end{array}$} & Eliminação de muco e hemácias \\
\hline & & Diminuição de amostras insatisfatórias \\
\hline & & Redução dos casos falso-negativos \\
\hline & & $\begin{array}{l}\text { Lâminas extras para realização de testes } \\
\text { moleculares e de captura híbrida }\end{array}$ \\
\hline & & Maior trabalho técnico \\
\hline & Aproximadamente 300 mil células para examinar & Maior custo \\
\hline & $\begin{array}{l}\text { Distribuição irregular das células e artefato de } \\
\text { técnica }\end{array}$ & $\begin{array}{l}\text { Necessidade de adaptação profissional à nova } \\
\text { técnica }\end{array}$ \\
\hline & Lâminas com material insuficiente & \\
\hline
\end{tabular}

CC: citopatologia convencional; LBC: citologia em meio líquido. 


\section{Tabela 2 Alterações nos procedimentos na conversão da CC para LBC}

\begin{tabular}{|c|c|c|}
\hline & CC & LBC \\
\hline Transferência do material & $\begin{array}{l}\text { Necessidade de passagem do material da } \\
\text { escova para a lâmina }\end{array}$ & $\begin{array}{l}\text { Acondicionamento direto da escova } \\
\text { impregnada em frasco com substância } \\
\text { fixadora }\end{array}$ \\
\hline Amostra & A maior parte do material é descartada & $\begin{array}{l}\text { Grande quantidade de material coletado } \\
\text { encontra-se na substância fixadora para } \\
\text { ser utilizado }\end{array}$ \\
\hline Fixação & Álcool ou spray fixador & $\begin{array}{l}\text { Imersão imediata e homogênea em solução } \\
\text { fixadora contendo metanol ou etanol }\end{array}$ \\
\hline $\begin{array}{l}\text { Preparado laboratorial } \\
\text { Necessidade de trabalho } \\
\text { manual antes de corar }\end{array}$ & Pronto para corar & Preparo semi-automático. \\
\hline
\end{tabular}

CC: citopatologia convencional; LBC: citologia em meio líquido.

trabalho foi comparar (quantitativa e qualitativamente) esfregaços orais preparados por meio da CC e da LBC.

\section{Material e métodos}

Foram realizados raspados na borda lateral da língua de seis voluntários (três homens e três mulheres) na faixa etária entre 20 e 30 anos, que apresentavam a mucosa oral com aspecto clínico normal. A coleta do material da borda esquerda da língua foi realizada pelo mesmo profissional.

Assim, foram testados três diferentes instrumentos de coleta: a escova endocervical (cytobrush), uma espátula plástica e a escova contida no kit da citologia em meio líquido utilizado no estudo (Câmara Múltipla de Sutta Lipa ${ }^{\circledR}$, LuPe Ind. e Com.), tanto para a CC como para a LBC, para avaliação da celularidade.

Em todos os voluntários foram realizados seis raspados, dois utilizando cada instrumento, com 24 horas de intervalo entre as coletas. O material da primeira coleta de cada instrumento foi processado por meio da LBC, de acordo com as instruções do fabricante. Com o material obtido na segunda coleta, foi realizado um esfregaço citopatológico convencional em lâmina de vidro e fixação imediata em álcool $96^{\circ}$ (Tabela 3).

Todas as lâminas foram coradas pelo método de Papanicolaou, e analisadas por dois observadores quanto à qualidade e à distribuição do material.

Para a avaliação da celularidade, fez-se a contagem de células em 20 campos que apresentavam maior concentração celular em cada lâmina, utilizando microscópio

\begin{tabular}{lll} 
Tabela 3 & & \\
\hline Dia & Coleta & Processamento \\
1 & Escova do kit & LBC \\
2 & Escova do kit & $\begin{array}{l}\text { Papanicolaou } \\
\text { convencional }\end{array}$ \\
3 & Escova endocervical & LBC \\
4 & Escova endocervical & Papanicolaou \\
& Envencional \\
5 & Espátula plástica & LBC \\
6 & Espátula plástica & Papanicolaou \\
& convencional \\
\hline
\end{tabular}

$\angle B C$ : citologia em meio líquido.

óptico com objetiva de aumento de 40 vezes. Foi feita a média aritmética dos resultados de cada observador. Os dados foram submetidos à análise estatística pelo teste $T$ para a comparação das médias, utilizando-se o software SPSS 11.0.

\section{Resultados}

Em relação ao método de coleta, não foi relatada qualquer dificuldade pelo profissional na manipulação dos três instrumentos em estudo. Entretanto, todos os voluntários concordaram que a espátula plástica proporcionou maior incômodo, seguida da escova do kit e da escova endocervical.

Quanto à quantidade de material, houve redução significativa nas lâminas obtidas na citologia em meio líquido, quando comparadas às da citopatologia convencional. Em amostras 
do mesmo indivíduo, notou-se ainda redução da quantidade de células inflamatórias e de colônias de bactérias.

Independente do instrumento utilizado na coleta, a LBC forneceu lâminas com distribuição celular mais regular e homogênea do que a CC. Além disso, embora ainda presente, observou-se redução da sobreposição celular nas lâminas confeccionadas por meio da LBC.

Ao comparar os instrumentos utilizados na coleta, a celularidade epitelial média nas lâminas da citologia em meio líquido obtidas com a espátula plástica foi de 5,4 células por campo; seguida pela escova endocervical (cytobrush), com 4,1 células por campo; e pela escova do kit, com 3,5 células por campo. Não houve diferença estatisticamente significativa entre esses resultados $(p>0,05)$.

\section{Discussão}

Uma vez que não houve diferença estatisticamente significativa na quantidade de células nos esfregaços obtidos pelos três instrumentos de coleta, utilizaram-se outros critérios para obter o mais adequado:

- escova do kit, por ser adaptada para ecto ou endocérvice, pode não apresentar boa adaptabilidade às diferentes topografias da cavidade oral; não sendo portanto muito indicada para esse fim;

- a espátula plástica, além de incômoda para o paciente, não é facilmente reproduzível e necessita ser esterilizada;

- a escova endocervical (cytobrush) foi considerada a mais adequada para utilização intra-oral, pois proporciona maior conforto aos voluntários, é comercializada em embalagens individuais e estéreis, e porque seu cabo longo permite fácil acesso às áreas mais difíceis.
Do material proveniente do raspado oral, após centrifugação, forma-se um pequeno pellet e possivelmente parte do material pode ser desprezado juntamente com o sobrenadante durante o processamento. Contudo, acredita-se que algumas modificações no protocolo, como o aumento do tempo de vórtice e de centrífuga, poderiam contribuir para a formação de um pellet mais significativo.

Embora nas amostras cervicouterinas a redução de células inflamatórias, de hemácias e de muco seja considerada uma vantagem da $\mathrm{LBC}{ }^{(2,7,9,18-20)}$, nos raspados orais muitas vezes esses elementos compõem aspectos significativos de determinada doença.

Devido ao reduzido tempo de observação na $L B C$, o material se concentra em uma pequena área da lâmina, ficando mais homogêneo, o que reduz consideravelmente o tempo de leitura das lâminas.

Apesar de estar presente em menor quantidade, a sobreposição celular não foi totalmente eliminada na citologia em meio líquido como a literatura relata, estando presente em algumas lâminas.

\section{Conclusões}

A citologia em meio líquido pode ser uma nova técnica a ser somada aos exames auxiliares de diagnóstico oral, pois parece proporcionar bons resultados. No entanto, como foi desenvolvida para exame de colo uterino, ainda são necessárias adaptações para que possa ser utilizada visando outros fins. Contudo, mais estudos são necessários para melhor adaptar a técnica à cavidade oral e avaliar seu desempenho.

\section{Referências}

1. ARAÚJO, M.S.; SOUSA, S.C.O.M.; CORREIA, D. Evaluation of cytopathologic exam for diagnosis of oral chronic paracoccidioidomycosis. Revista da Soc Bras Med Tropical, v. 36, n. 3, p. 427-30, 2003.

2. ALVES, A.V. et al. Comparison of manual and automated methods of liquid-based cytologya: a morphologic study. Acta Cytologica, v. 48, n. 2, p. 187-93, 2003.

3. BERGERON, C.; FAGNANI, F. Performance of a new liquidbased cervical screening technique in the clinical setting of a large French laboratory. Acta Cytologica, v. 47, n. 5, p. 753-61, 2003.
4. BERNSTEIN, S.J. etal. Liquid-based cervical cytology smear study and conventional pap: a meta-analasys of prospective studies comparing cytologic diagnosis and sample adequacy. Am J Obstet Gynecol, v. 185, p. 308-17, 2001.

5. DIAS, E.P. et al. Diagnóstico clínico e cito-histopatológico das manifestações bucais na AIDS. JBDST, v. 10, n. 1, p. 10-6, 1998.

6. DIAS, E.P. et al. Oral hairy leukoplakia: histophatologic and cytopathologic features of a subclinical phase. Am J Clin Pathol, v. 114, p. 394-400, 2000.

7. HAYAMA, F.H.; MOTTA, A.C.; SILVA, A.P.G. Preparados de base líquida vs. citología convencional: adhesión de las muestras 
y coincidencia del diagnóstico en lesiones orales. Med Patol Oral y Cir Bucal, v. 10, p. 115-22, 2005.

8. HERBERT, A.; JOHSON, J. Personal view: is it reality or an illusion that liquid-based cytology is better than conventional cervical smears? Cytopathology, v. 12, p. 383-9, 2001.

9. HOELUND, B. Implementation of liquid-based cytology in the screening programme against cervical cancer in the County of Funen, Denmark and status for the first year. Cytopathology, v. 14, n. 5, p. 269-74, 2003.

10. KLINKHAMER, P.J. et al. Liquid-based cervical cytology. Cancer, v. 99, n. 5, p. 259-62, 2003.

11. McGOOGAN, E. Liquid-based cytology the new screening test for cervical cancer control. J Fam Pkann Reprod Health Care, v. 30, n. 2, p. 123-5, 2004.

12. MEHROTRA, R. et al. Application of cytology and molecular biology in diagnosing premalignant or malignant oral lesions. Molecular Cancer, v. 5, p.11-9, 2006.

13. MELAMED, M.R. Liquid-based cytology and conventional cervical smears. Comment on Cancer, v. 25, n. 6, p. 331-5, 2003.

14. MINGE, L. et al. Autocyte prep system vs. conventional cervical cytology: comparison based on 2.156 cases. J Reprod Med, v. 45, p. 179-84, 2002.
15. MOSELEY, R.P.; PAGET, S. Liquid based-cytology : is this the way forward for cervical screening? Cytophatology, v. 13, p. 71-82, 2002.

16. OBWEGSER, J.H.; BRACK, S. Does liquid-based technology really improve detection of cervical neoplasia? A prospective, randomized trial comparing the Thin Prep Pap test with conventional Pap test, including follow-up of HSIL cases. Acta Cytologyca, v. 45, p. 709-14, 2001.

17. PAYNE, N., et al. Liquid-based cytology for cervical screening. Cytopahology, v. 11, p. 469-70, 2000.

18. PEREIRA, S.M.M. et al. Avaliação da celularidade citológica em preparados de base líquida. Ver Inst Adolfo Lutz, v. 62, n. 1, p. 35-9, 2003.

19. SASS, M.A. Use of a liquid-based, thinlayer pap test in a community hospital: impact on cytology performance and productivity. Acta Cytologyca, v. 48, n. 1, p. 17-22, 2004.

20. SCHLEDERMANN, D. et al. Significance of atypia in conventional Papanicolaou smears and liquid-based cytology. Cytopathology, v. 15, p. 148-53, 2004.

21. TAKAHASHI, I. et al. Coexistence of Pemphigus vulgaris and Herpes simplex virus infection in oral mucosa diagnosed by cytology, immunohistochemistry, and polymerase chain reaction. Diagn Cytopathol, v. 19, n. 6, p. 446-50, 1998. 